found freely moistened with mucus, and relaxed; the patient expressed herself as relieved from a sense of great oppression, and the pains now became more of a bearingdown character. At four, a.m., I was informed that the head had entered the cavity of the pelvis. At nine, a.m., the pains having again become inefficient, I was requested to see the patient again, whom I found desponding and spiritless. At the desire of my friend I remained in the room, and having somewhat encouraged the patient, the uterine action returued in full vigonr in the course of a few minutes, and the child was born within twenty minutes afterwards, without any further interference. Ifter the birth hæmorrbage supervened, which, with her, had been an usual occurrence. The placenta, not morbidly adberent, was separated from its attachment and brought away, and the uterus readily contracted. For the sake of security, however, against relaxation of the organ, and a consequent recurrence of the hrmorrhage, the T-bandage and compress were applied. Her recovery was as rapid as after any former confinement.

ARM - PRESENTATION - THE CHILD PUTRIDDELIVERY BY EMBRYOTOMY.

Sept. 6, 1837, nine o'clock, a.m. I was requested by Mr. Hunt, formerly housesurgeon at University College Hospital, to visit a patient to whom he had just been called, in labour with her eleventh child. The pains had commenced on Monday morning, at half-past four o'clock, a.m., and at two, p.m., the parish midwife was fetched. The liquor amnii was discharged at four, p.m., after which the pains flagged. The surgeon for the district was sent for, but not wishing to undertake the delivery, the case was left without further aid till the time of Mr. Hunt's being called in.

The following was the state in which $I$ found the patient:-Pains strong; a hand protruding through the outlet, with the palm directed to the hollow of the sacrum; the arm and presenting part of the trunk much swollen; the skiu peeling off from the extremity in several places. On making a cautious attempt to turn the child $I$ found the uterus strongly resisting my efforts. The pulse being 120 and hard, skin hot and dry, and some distress being felt about the head, blood was taken from the arm; my friend withdrew thirty ounces in a full bounding stream. The patient did not feel in the least faint, but expressed herself thankful for the relief which it brought her. The child being dead and the uterus firmly contracted upon its body, I determined, without further loss of time, to deliver by the only means which remained to me, namely, by embryotomy. The chest was perforated beneath the scapula, and a considerable quantity of putrid gas discharged from the cavity of the trunk. Some of the viscera were removed, and upon traction being now applied by a blunt hook, the foetus was readily brought down. The head, by reason of its putrid state, freely collapsing, offered but little obstruction to the progress of the diminished trunk. The child having been born, the uterus contracted and urged the placenta into the vagina, whence it was at once removed.

Visit at half-past seven, p.m. Has passed urine in considerable quantity and without pain; feels very comfortable; pulse 78; tongue clean.

Sept. 7. Pulse 78; tongue clean; no pain. The bowels have been opened by castor oil.

8. No pain; pulse 84 , being a little excited by the removal of the child for burial.

9. Skin cool; sleeps well ; tongue quite clean; pulse 78. Ordered castor oil, as the bowels have not been moved since the $r$ th.

10. The bowels have acted three times. Her recovery now progressed rapidly.

\section{ON IARGE DOSES OF THE NITRATE OF POTASS.}

\section{To the Editor of The LanceT.}

SIR,-In your report of the discussion which took place at the London Medical Society on the 22nd of January, I have just read that Dr. Johnson, Dr. Willshire, and Mr. Headland, expressed their conviction that the large doses of nitre taken by the patient whose case was under consideration might have been the cause of inflammation and suppuration of the kidney. The patient in question had taken two drachms, three times a day, previous to the attack. Dr. Johnson also stated that he bad seen half-drachm doses very injurious to the stomach.

Having, during several years, seen the nitrate of potass extensively administered in very large doses, and having myself often thus prescribed it, I am able to assert, with the greatest confidence, that the opinions delivered by the gentlemen who took part in the above debate, unless qualified, are totally unfounded. The nitrate of potass is, certainly, an irritant poison, and capable of giving rise, as such, to inflammation and perforation of the stomach, if administered in large doses, but only when taken in the form of a powder, or of a very concentrated solution. When largely diluted in a fluid one or even two ounces may be taken in the four and twenty hours, not only without giving rise to any toxical symptoms, but with great benefit in certain morbid states of the economy.

This must appear a rather startling fact to those who have formed their opinions respecting the properties of nitre, not from their own experience, but from modern 
works on materia medica and toxicology. Thus, in the last edition of Thomson's "Dispensatory," I find the extreme dose which can be taken in safety stated as two drachms. In very large doses, such as from four drachms to one ounce, says Dr. Thomson, it occasions vomiting, hypercatharsis, bloody stools, convulsions, and sometimes death. Beck, in his "Elements of Medical Jurisprudence," gives several cases in which doses varying from an ounce and a half to two ounces, proved fatal, and others in which the patients recovered, but after experiencing all the symptoms of poisoning by an irritant substance, and suffering for months. Every medical man is acquainted with the interesting experiments of Orfila on dogs, with reference to the action of the various poisons. He found that the ingestion of five drachms and a half produced death if the osophagus was afterwarts tied. Christison, in his admirable "Treatise on Poisons," considers nitre in the same light as the other anthors whom $I$ have men. tioned, and brings forward several fatal cases extracted from various sources. With his usual discrimination, however, he appears to perceive that the toxical properties of the nitrate of potass have been much exaggerated, and states that a gentleman of his acquaintance once took an ounce by mistake for Glauber's salts, and retained it above a quarter of an hour, without experiencing any other unpleasant symptom than several attacks of vomiting. He also mentions the experiments of Dr. Alexander, who found that he could himself take as much as an ounce and a half of nitre in the twentyfour hours, if largely diluted, without experiencing any bad effects from its ingestion; and the instance related by M. Tourtelle, where two ounces were retained altogether, and caused only moderate griping, with considerable purging and flow of urine.

In reality, the key to the different results exhibited in the above cases is to be sought for, not in idiosyncrasy or constitutional insensibility, engendered by disease, as Dr. Christison at first suggests, but in "difference in the mode of administration," which he mentions lastly as a possible explanation. When the nitrate of potass is given in a small compass, and in a single dose, half an ounce will act as an irritant poison, and occasion acute inflammation of the mucous surfaces; but if it is largely diluted a much greater quantity may prove innocuous, even if given in one dose, and is sure to prove so if administered in divided doses during the twenty-four hours.

It is principally in acute rheumatism that large doses of the nitrate of potass have been given. From some researches made by one of $\mathrm{my}$ friends and late colleagues, $M$. Aran (Journ. des Connais. Medico-Chirur., 1841), it would appear that the nitrate of potass was used in large doses in the treat- ment of rheumatism during the last century by several English physicians, whose names $I$ am unable to mention, not having $M$. Aran's paper by me. At a late discussion on the subject, which took place at the Académie de Medicine, it was stated that several Italian physicians of the modern school had thus administered it, and that twenty years ago, in Paris, M. Kapler, phy. sician to the Hôpital St. Antoine, and M. Bagneris, physician to the Invalides, had also given nitre in large doses in the above. named disease.

I believe, however, that M. Gendrin, the physician to the Hópital de la Pitié, is, of all modern physicians, the one who has paid the greatest attention to the therapentic properties of large doses of the nitrate of potass in rhe umatism. After trying, comparatively, the efficacy of the various plans of treatment which are resorted to in acute rheumatism, he has given the superiority to large doses of the nitrate of potass, and for many years has had recourse to no other therapentic agent in the great mass of his cases. Owing to this circumstance, during nearly three years which I passed with M. Gendrin, either as clinical clerk or house-physician, all tho cases of acute rheumatism which came into the wards were treated by nitre, in doses varying from six to twelve or sixteen drachms in the four and twenty hours, according to the age, sex, or constitution of the patient. The number of cases which I have seen thus treated nust, therefore, be great when we consider that more than two thousand patients sojourn in MI. Gendrin's wards each year. Indeed, although I have kept no sta. tistical record, I should say that I have seen treated, or treated myself, at La Pitié, in this manner, at least, seventy or eighty persons labouring under acute rheumatism.

With women we generally commenced with six drachms, rapidly increasing the quantity to eight, ten, or twelve. With men we generally began at once with an ounce, gradually increasing the dose to ten, twelre, fourteen, or sixteen drachms. In the very great proportion of cases, however, M. Gendrin did not exceed the dose of twelve drachms, or approve of its being exceeded. The salt was always administered dissolved in a large quantity of barley-water, sweetened with sugar, the proportion being about half an ounce to a pint and a half or two pints of fluid. This was the only beverage allowed to the patient, and taken by him as required.

In this large number of cases $I$ do not remember once seeing any toxical symp* toms produced. The secretions of the skin and kidueys were generally increased, and sometimes those of the intestinal canal, but the principal action of the nitre seemed to be a sedative action, the pulse generally falling rapidly, both as regards frequency and strength. It is, no doubt, to this sedative, 
contra-stimulant action that we must look to explain its undeniable efficacy in the treatment of acute rheumatism. Although the narcotic action of nitrate of potass is generally admitted, it is but little insisted on. The experiments of Orfila, however, cannot leave a doubt on the subject in the mind of any one who has perused them; the death of the dogs to which nitre was administered being preceded by giddiness, slight convulsions, dilated pupils, insensibility, and palsy. It is only in a very few instances that $I$ remem. ber having seen vomiting follow the ingestion of the fluid containing the nitre, and then it was but slight, and soon ceased, without its being necessary to discontinue the use of the medicinal agent.

I do not recollect having once seen any symptoms of renal irritation or inflammation produced by these large doses of nitvate of potass, and have never heard M. Gendrin, whose experience on the subject is necessarily very great, say that he had met with such a case. MI. Martin Solon, in the com. munication which he made last October to the Academy, on the treatment of acute rheumatism by large doses of nitre, does not mention having observed a single instance of renal affection in the thirty-three cases which he had treated by doses varying from one to two ounces. It cannot be said of these two physicians that renal affections may have presented themselves without their having perceived it, as they are both accurate and conscientious observers, and have both paid particular attention to the pathology of the kidneys. M. Martin Solon, indeed, is the author of one of the best French works on "albuminuria" which has yet appeared.

$I$ have myself not only administered an ounce or more of nitre in the four-and-twenty hours, for many days consecutively, in acute rheumatism, but also in puerperal fever and in other inflammatory diseases, with, I think, marked benefit, and without ever observing any toxical symptom.

I believe I have said enough to prove that in the case brought before the London Medical Society by Mr. Dendy, the three or six drachms taken by the patient previous to the attack can scarcely be looked upon as the cause of inflammation or suppuration of the kidney. If he took it sufficiently diluted it would have done him no harm, and if undiluted, the stomach is the organ which would have been principally injured, and not the kidneys. As I have been induced, in thus discussing the toxical and therapeutical properties of nitre, to speak of its use in the treatment of rheumatism, I shall take an early opportunity of stating what $I$ know on that subject. I remain, Sir, your obedient servant,

Henry Bennet, M.D.

Cambridge-square, Hyde-park, Jan, 28, 1844.
MR. GREENHOW ON HIS CASE OF OVARIAN OPERATION.

To the Editor of The Lancet.

Sir,-If the report, in THE LA NCET, of the discussion which took place at the Medical and Chirurgical Society, when my case of operation for the removal of a diseased ovarium was read, had not differed in words, at least, if not in substance, from that which I had previously seen in the "Medical Times," I should have requested you to copy into The LANCET a letter of explanation which I had addressed to the Editor of that journal.

Had I been present on the occasion referred to, a few words at the time would have sufficed to remove misapprehensions which appear to have been entertained by two gentlemen who joined in the discussion; they must not, however, be permitted to go forth to the profession unnoticed.

In the last week's LanceT Mr. Bransby Cooper is reported to have said,_."With respect to Mr. Greenhow's case, he thought its history, the slight fluctuation in, and the position of the tumour, did not justify the operation. The nature of the tumour, as evinced in the drawings before the society, proved this to be the case; for, instead of being transluscent, as ovarian cysts usually were, this was of a solid character."

Mr. Cooper's expression, "did not justify the operation," is a strong one, which our hitherto limited knowledge and experience of this operation in no degree justifies; and when we reflect on the history and termination of his own case, which was read on the same evening, I cannot but feel both surprise and regret that Mr. Cooper should have been led to censure in another surgeon an operation which he had himself performed under circumstances certainly not less questionable. And on what ground does $\mathrm{Mr}$. Cooper make this hasty assertion? Simply because of "the slight fluctuation in the tumour", and that "instead of being transluscent, as ovarian cysts usually were, this was of a solid character." I have nowhere seen these conditions laid down as diagnostic signs of the fitness of an ovarian tumour for extirpation, by gentlemen who have practised the operation with greater success than either Mr. Cooper or myself; and a reference to the description of ovarian tumours removed by Dr. Clay (and, I believe, others) will prove that considerable portions, at least, consisted of solid matter, very similar to that described in the case related by myself. Surely the success of Dr. Clay's cases in no degree depended on the quantity of fluid contained in the cysts.

Mr. Lawrence's remarks appear to me very judicious. Speaking of cases consisting of fluid principally, Mr. L. observes, " Now these were just the kind of cases in 